\title{
Importance of telecommunications in the times of COVID-19
}

\author{
Muhammad Khurram Khan ${ }^{1}$
}

Accepted: 14 December 2020 / Published online: 12 January 2021

(c) The Author(s), under exclusive licence to Springer Science+Business Media, LLC part of Springer Nature 2021

We will never forget the year 2020 due to COVID-19 pandemic, which brought an unprecedented health and socioeconomic crisis to the human history. The current pandemic has become an earth-shattering calamity for the well-being and livelihoods, and has created multifaceted inequalities at the global level. It seems quite obvious that the continuous growth, competitiveness, and business development of the world may remain uncertain in the foreseeable future. With all its effects, the pandemic has familiarized us with several keywords and phrases that were not commonly used in our daily lives e.g., new norm, social distancing, quarantine, lockdown, and work from home, etc. Consequently, this situation has underpinned the importance of digital connectivity to keep our communities connected so that the negative socio-economic effects could be diminished.

To adopt new realities and continue with the normal routines, telecommunication infrastructure and its services are playing a significant role to keep individuals and organizations connected and running. A great global surge in the usage of information and communication technology has been observed in recent times due to online education, work and entertainment etc. It shows that telecommunications field is the key enabler of not just connectivity, but also of productivity to keep the world progressing due to the disruption caused by the pandemic. However, this all is not possible without the relentless efforts and hard work of researchers, scientists, engineers, technicians and professionals who are continuously innovating and contributing to this field.

As far as the research aspect of telecommunications and its underlying technologies is concerned, we have witnessed a large number of publications and patent applications around the globe during recent times. There is a possibility that the current situation has given a great impetus and encouragement to the research community to come up with

Muhammad Khurram Khan

mkhurram@KSU.EDU.SA

http://www.professorkhurram.com

1 Telecommunication Systems (Springer-Nature), King Saud University, Riyadh, Saudi Arabia better research outcomes in addressing the ongoing challenges. Our journal, Telecommunication Systems, has also observed an increased number of submissions during the last few months. We have received 455 submissions in the first three quarters of 2020, which is a significant increase from 408 submissions in 2019 and 398 in 2018, respectively. We are indeed grateful to the authors for their valuable contributions and trust in Telecommunication Systems.

While these are certainly unprecedented and chaotic times, we must appreciate the services of our editorial board members and reviewers who are facilitating the peerreview process of the journal. It is a pleasure to mention that the turnaround time for the first decision has surprisingly reduced to 49 days during the first three quarters of 2020 , which was recorded 81 days in 2019 and 73 days in 2018, respectively. Of course, this all is made possible due to the great efforts of our editorial board members and reviewers for their timely actions to perform the peer-review process. Besides, we cannot forget to recognize and compliment the services of departing editorial board members who dedicated their precious time and efforts to serve the journal. We also welcome new editorial board members who have shown great passion to assume their services with the same zeal of their predecessors. We hope that their induction to the editorial board would help in improving the quality of contents published by the journal.

We are also indebted to our editorial office staff who are always a step ahead to provide the best editorial services to our authors, reviewers and editors. We would like to extend sincere thanks and appreciation to our journal's editorial assistant, Ms. Kanishkaa Sridhar, for the seamless editorial workflow. Our production editor, Ms. Radika Devakumar, has always been instrumental in publishing the journal's contents in time and she deserves a huge thanks. Our new editorial assistant at Springer-Nature, Ms. Angelina HuberFeely, is assisting us in a very efficient manner to update the journal's website and the masthead. The support of Mr. Matthew Amboy, a senior editor at Springer-Nature, is a source of motivation for us to improve the quality of the journal. 
At the end, we hope to defeat the COVID-19 pandemic and its associated challenges in 2021. We also wish our readers, authors, reviewers, editorial staff, and editorial board members a happy, healthy and prosperous new year!

Publisher's Note Springer Nature remains neutral with regard to jurisdictional claims in published maps and institutional affiliations.

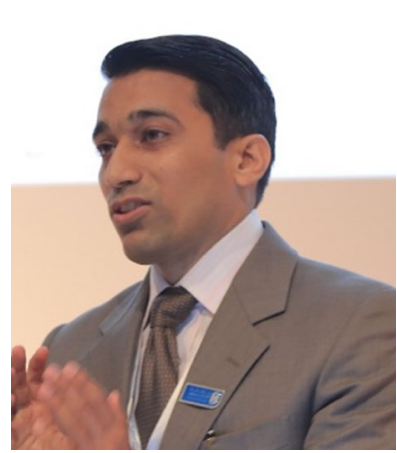

Muhammad Khurram Khan is currently working as a Professor of Cybersecurity at the Center of Excellence in Information Assurance, King Saud University, Kingdom of Saudi Arabia. $\mathrm{He}$ is founder and CEO of the 'Global Foundation for Cyber Studies and Research' (http:// www.gfcyber.org), an independent and nonpartisan cybersecurity think-tank in Washington DC, USA.
He is the Editor-in-Chief of 'Telecommunication Systems' published by Springer-Nature with its recent impact factor of 1.73 (JCR 2020). He is on the editorial board of several journals including, IEEE Communications Surveys \& Tutorials, IEEE Communications Magazine, IEEE Internet of Things Journal, IEEE Transactions on Consumer Electronics, Journal of Network \& Computer Applications (Elsevier), IEEE Access, IEEE Consumer Electronics Magazine, PLOS ONE, and Electronic Commerce Research, etc. He has published more than 380 papers in the journals and conferences of international repute. In addition, he is an inventor of 10 US/PCT patents. He has edited 10 books/ proceedings published by Springer-Verlag, Taylor \& Francis and IEEE. His research areas of interest are Cybersecurity, digital authentication, IoT security, biometrics, multimedia security, cloud computing security, cyber policy, and technological innovation management. He is a fellow of the IET (UK), a fellow of the BCS (UK), and a fellow of the FTRA (Korea). He is the Vice Chair of IEEE Communications Society Saudi Chapter. He is a distinguished Lecturer of the IEEE. His detailed profile can be visited at http://www.professorkhurram.com. 